\title{
Representações sociais da humanização do cuidado na concepção de usuários hospitalizados
}

\section{Social representations of care humanization in the conception of hospitalized users}

\author{
Isis de Moraes Chernicharo \\ Enfermeira. Mestranda em Enfermagem pela Escola de Enfermagem \\ Anna Nery/UFRJ. Membro do Núcleo de Pesquisa em Fundamentos \\ do Cuidado de Enfermagem (NUCLEARTE), da EEAN; Bolsista CNPq \\ (2012) e Bolsista FAPERJ nota 10 (2013). \\ Endereço: Estrada da Água Grande, 1202, Rua 08, Casa 32, Vista \\ Alegre, CEP 21230-355, Rio de Janeiro, RJ, Brasil. \\ E-mail: isischernicharoळhotmail.com \\ Fernanda Duarte da Silva de Freitas \\ Enfermeira. Mestre em Enfermagem. Doutoranda do Programa \\ de Pós-Graduação em Enfermagem da EEAN-UFRJ. Membro do \\ NUCLEARTE. Bolsista CAPES. \\ Endereço: Rua Jordão, 510, casa 197, Taquara, CEP 22725-540, Rio \\ de Janeiro, RJ, Brasil. \\ E-mail: fernanda23_dasilvaळyahoo.com.br

\section{Márcia de Assunção Ferreira} \\ Doutora em Enfermagem. Professora Titular do Departamento de \\ Enfermagem Fundamental da EEAN/UFRJ. Pesquisadora do CNPq. \\ Endereço: Estrada do Capenha, 155, ap. I01, Freguesia-Jacarepaguá, \\ CEP 22743-041, Rio de Janeiro, RJ, Brasil. \\ E-mail: marciadeaf®ibest.com.br
}

\section{Resumo}

As Representações Sociais relacionam conhecimentos e ideias novas que se apresentam ao sujeito, com valores, ideias e teorias preexistentes e internalizadas na cultura, buscando a construção de uma realidade comum a um conjunto social. Portanto, esta pesquisa tem como objetivo identificar os elementos que constituem as representações dos usuários hospitalizados sobre a humanização do cuidado. É uma pesquisa qualitativa tendo como sujeitos quinze usuários hospitalizados no setor de clínica médica de um hospital universitário público federal do município do Rio de Janeiro - RJ. Foram realizadas entrevistas individuais e observação sistemática. As concepções dos sujeitos sobre humanização remetem às relações estabelecidas entre o profissional e o usuário no cuidado, e à política gestora da saúde-assistência. Nesse sentido, a lógica de construção das ideias dos usuários sobre humanização passa tanto por questões de caráter objetivo (gestão, mudança nas práticas e comportamentos) como de caráter subjetivo (empatia, relações profissional-cliente e questões emotivas), o que indica que a humanização tem uma vertente mais ampla, que atravessa de forma mais geral os grupos sociais, e uma vertente mais restrita, que responde aos contextos situacionais das vivências cotidianas dos sujeitos. Conclui-se que a humanização do cuidado tem estreita relação com o binômio saúde e sociedade, entendendo sociedade como o contexto no qual se inserem os sujeitos que participam do processo da saúde, como expressão das políticas e objeto mesmo a ser buscado como condição digna de vida.

Palavras-chave: Enfermagem; Humanização da assistência; Psicologia social. 


\section{Abstract}

Social representations relate new knowledge and ideas that are presented to the subject to existing values, ideas and theories in the background and internalized culture, seeking to build a common reality to a social group. Therefore, this research aims to identify the elements that constitute the representation of hospitalized users of the humanization of care. It is a qualitative research whose subjects were fifteen hospitalized users in the medical clinic department at a federal university hospital, on the municipality of Rio de Janeiro - RJ. Individual interview and systematic observation were used to generate data. The conceptions of the subjects on humanization refer both to the relationships between professionals and users in care and to management and politics of healthcare. In this sense, the logical construction of users' ideas about humanization derives from objective (management, change in practices and behaviors) and subjective (empathic, professional-client relationship and emotional issues) reasons. This fact indicates that humanization has a broader aspect, which traverses in a more general way the involved social groups, and a narrower aspect which responds to the situational contexts of everyday experiences of the subjects. It can be concluded that the humanization of care is closely related to the binomial health and society, society understood as the context in which are inserted the individuals participating in the process, as well as expression of healthcare policies and as an object to be searched as a worthy condition of life.

Keywords: Nursing; Humanization of Assistance; Psychology; Social.

\section{Introdução}

A Teoria das Representações Sociais (TRS) tem como objetivo explicar os fenômenos humanos a partir de uma perspectiva coletiva, sem perder de vista a individualidade (Moscovici, 2010). A realidade é socialmente construída e o saber é uma construção do sujeito, mas não desligada da sua inscrição social, e sim operacionalizada em um conceito para trabalhar com o pensamento social em sua dinâmica e em sua diversidade (Arruda, 2002). Assim, para conhecer as Representações Sociais de um determinado objeto é necessário compreender que a produção de conhecimentos plurais constitui e reforça a identidade dos grupos, influenciando em suas práticas e reconstituindo seu pensamento (Oliveira, 2004).

As Representações Sociais (RS) relacionam conhecimentos e ideias novas que se apresentam ao sujeito, com valores, ideias e teorias preexistentes e internalizadas na cultura, buscando a construção de uma realidade comum a um conjunto social (Arruda, 2002). Para tal, os estudos de RS, de um modo geral e, em especial, na área do cuidado em saúde requerem do pesquisador uma determinada sensibilidade, pois é necessário perceber que o contexto é o cenário principal para distinguir a diversidade de olhares e vozes que caracterizam os grupos sociais (Nascimento-Schulze e Camargo, 2000).

Sendo assim, a Representação Social está relacionada com as infinitas trocas simbólicas que se dão nas relações interpessoais no ambiente social. Neste, consideram-se a cultura, a linguagem e a comunicação, os valores, contexto ideológico e histórico, inserção social dos sujeitos - sua posição e filiação grupal (Moscovici, 2010). Todas essas relações influenciam na construção de um conhecimento compartilhado que passa a ser explicado pela complexa subjetividade humana.

Deste modo, não se pode falar de RS da humanização do cuidado sem antes entender o que é a complexidade e como esta se relaciona com o cuidado humano.

A complexidade pode ser definida pelo que não pode resumir-se em uma ideia simples ou em uma palavra mestra. A complexidade aspira ao conhecimento multidimensional compreendendo fenômenos aleatórios, incertezas, liberdade, criatividade, 
autonomia e individualidade (Morin, 2011). Desta maneira a compreensão da complexidade humana implica, entre tantas outras questões, na subjetividade, pois cada pessoa tem características próprias, devendo ser valorizada como um ser global, questão essa que vai ao encontro da TRS.

Portanto, há uma estreita relação das RS com a complexidade humana. Em face disso, pressupõe-se que, ao se abordar a humanização articulando elementos afetivos, mentais e sociais, integrando elementos da cognição, linguagem e comunicação, evidenciando as relações sociais que afetam as representações e a realidade material, social e ideal (das ideias) sobre a qual elas vão intervir, ela se torna concreta e alcançável, possibilitando a efetiva implementação dos preceitos propostos pela Política Nacional de Humanização (PNH) (Moscovici, 2010; Brasil, 2004).

A PNH foi implantada em 2004 pelo Ministério da Saúde, abrangendo todos os níveis de atenção à saúde, perpassando outras políticas e programas, no intuito de afirmar a humanização no cotidiano das práticas de gestão e produção do cuidado em saúde. No que tange aos usuários, a PNH objetiva garantir a efetiva aplicação dos princípios do Sistema Único de Saúde (SUS) - integralidade, universalidade e equidade na saúde - com garantia de acesso articulada ao seu efetivo atendimento, promoção de qualidade de vida e respeito à subjetividade.

Para tanto, buscar as RS da humanização do cuidado na concepção dos sujeitos que vivem o cuidado, na condição de usuários, possibilitará acessar como tal termo vem sendo difundido no âmbito assistencial, identificando sua influência nas práticas profissionais. Assim, esta pesquisa se propõe a acessar os saberes individuais e coletivos acerca das concepções de usuários hospitalizados sobre a humanização do cuidado, identificando os elementos que as constituem.

\section{Metodologia}

Esta é uma pesquisa qualitativa de abordagem exploratória e descritiva, cujo referencial conceitual foi extraído da Teoria das Representações Sociais (TRS) na linha da psicossociologia (Moscovici, 2010). Ademais, dados quantitativos sobre os sujeitos servirão de apoio, subsidiando as discussões dos resultados, uma vez que à luz da TRS, as concepções dos sujeitos amparam-se na identidade dos grupos aos quais pertencem.

Os sujeitos foram usuários adultos hospitalizados, de ambos os sexos, escolhidos a partir da aplicação de critérios de inclusão: no período de execução da pesquisa deveriam estar lúcidos e orientados no tempo e no espaço, e com a comunicação verbal preservada. Como critérios de exclusão, foram aplicados os seguintes: ter comprometimento cognitivo, de consciência ou de comunicação verbal, que impedisse o diálogo e a realização das entrevistas, estarem com patologias que exigissem isolamento de contato e/ou respiratório. Vale considerar que, na época em que foi realizada a produção dos dados da pesquisa, o hospital que serviu de cenário para o estudo estava passando por um surto epidemiológico da bactéria Acinetobacter. Sendo assim, houve uma pré-seleção dos usuários a partir da leitura dos seus respectivos prontuários.

O cenário foi o setor de clínica médica de um Hospital Universitário público federal do município do Rio de Janeiro - RJ. De um total de 38 usuários hospitalizados neste setor, 27 atenderam aos critérios de inclusão, porém apenas 15 aceitaram participar da pesquisa.

Os dados foram produzidos no mês de fevereiro de 2010, com aplicação das técnicas de entrevistas individuais, seguindo um roteiro semiestruturado composto de duas partes. Na primeira, constam perguntas sobre o perfil sociodemográfico dos sujeitos, que se impõe ao referencial conceitual adotado, pois se faz necessário traçar as condições de produção das ideias e concepções dos sujeitos uma vez que estas se assentam nas marcas de pertença e de suas identidades socioculturais. Na segunda parte, constam perguntas abertas sobre os saberes e vivências dos usuários sobre a humanização do cuidado.

Além da entrevista semiestruturada, esta pesquisa inclui outra técnica de produção de dados: a observação sistemática, tendo como referencial a descrição densa que orienta tanto a observação, o registro como a análise de dados textuais, no intuito de minimizar os vieses da interpretação (Geertz, 1989).

Para a análise do material, utilizaram-se técnicas de análise de duas naturezas: quantitativa, 
com aplicação de recursos da estatística simples e percentual aos dados oriundos da primeira parte do instrumento (dados sociodemográficos), e qualitativa, com aplicação dos recursos das técnicas de análise temática de conteúdo (Bardin, 2011), aos dados oriundos das questões abertas.

Em atendimento à Resolução 466/12 do Conselho Nacional de Saúde, o projeto de pesquisa foi aprovado no Comitê de Ética e Pesquisa da Escola de Enfermagem Anna Nery, da Universidade Federal do Rio de Janeiro, protocolo ${ }^{\circ}$ o98/2009. 0 Termo de Consentimento foi assinado por todos os sujeitos. $\mathrm{O}$ anonimato foi garantido pela identificação alfanumérica dos depoimentos, cuja letra U significa Usuários, a letra M significa Masculino e a letra F feminino, seguidos de números arábicos que indicam a idade dos sujeitos, com hífen separando o número indicativo da sequência de realização da entrevista.

\section{Apresentação e discussão dos dados}

\section{Sobre as características gerais de identificação dos sujeitos}

Dos 15 usuários que participaram da pesquisa, 10 $(66,67 \%)$ eram do sexo feminino e 05 (33,33\%) do sexo masculino. Deste grupo, a maioria encontrava-se na faixa etária referente a 41-6o anos (6o\%) e apresentava, em sua maioria, o estado civil referente à situação de casado (40\%) e solteiro (33,33\%).

0 fato de a maioria de usuários hospitalizados pertencerem à faixa etária entre 41 e 60 anos remete ao fato de esta faixa etária estar relacionada com o aparecimento/diagnóstico de doenças crônicas não transmissíveis como a hipertensão e diabetes, associados ou não aos fatores de riscos (tabagismo, sedentarismo, antecedentes familiares, entre outros) que auxiliam no seu aparecimento (Toscano, 2004). As doenças crônicas não transmissíveis são mais diagnosticadas nessa faixa etária justamente por serem caracterizadas pelo progresso lento e silencioso. Desta forma, os sinais e sintomas começam a aparecer nos arredores desta faixa etária, levando o indivíduo a procurar assistência médica, acarretando, em muitos casos, a necessidade de internação para controlar ou reabilitar o usuário.

O perfil econômico dos sujeitos da pesquisa caracterizou-se, em sua maioria, pela renda familiar entre 1 e 2 salários mínimos (40\%) e pela moradia ser própria $(73,34 \%)$.

A questão econômica torna-se muito importante no momento que começa a interferir no tratamento do indivíduo. Esse quadro aparece na verificação de diversos problemas de infraestrutura hospitalar que requer que o usuário participe de seu tratamento, como, por exemplo, através da compra de medicamentos. Esta questão será mais bem explorada ao longo da discussão dos dados desta pesquisa.

\section{Categorias temáticas}

Sobre os dados oriundos da análise temática de conteúdo, dois temas se mostraram como organizadores dos discursos dos sujeitos sobre a humanização do cuidado: um remete às relações humanas e o outro à política gestora da saúde-assistência. Nesse sentido, a lógica de construção das ideias dos usuários sobre humanização passa por questões de nível macro, que mostram o contexto maior no qual se insere a assistência, e também de nível micro, que mostram as relações entre o profissional e o usuário no cuidado. Observa-se, no entanto, que é no cotidiano mesmo da assistência, portanto, na qualidade destas relações, que irão se evidenciar elementos que atribuem o status da humanização ao cuidado.

\section{A pragmática da assistência e as práticas de cuidado: elementos da relação humana caracte- rizadores da humanização}

Esta categoria abrange elementos constitutivos passíveis de serem identificados, tanto na análise dos depoimentos dos sujeitos quanto nos registros em diário de campo. A ênfase se dá nas relações interpessoais que se estabelecem no cuidado e mostram questões afetas à objetividade e à subjetividade da relação humana.

\section{Contexto situacional do cuidado: o usuário e o ambiente}

O contexto em que o sujeito está inserido pode interferir tanto no tratamento quanto na reabilitação do indivíduo.

Poxa, eu pedi ao médico, avisei para ele: 'Doutor não me põe sangue... não me transfunde, por causa da minha religião'[...], ai a anestesista falou: 'avisa para ele que se precisar nós vamos colocar sangue, ai eu falei: 'Não, então tem que parar tudo', aí o 
médico falou: 'Não, pode ficar tranquilo. Não vai ter transfusão não'. E realmente não foi necessário (UM50-04).

A negociação do cuidado é uma dimensão importante a se considerar no campo da humanização, principalmente quando se observa que o contexto sociofamiliar e religioso do usuário pode influenciar nas decisões e na assistência a ser prestada. A unidade de registro que exemplifica esta questão mostra que o que direciona o aceite do usuário a um determinado procedimento, no caso a transfusão sanguínea, é uma diretriz religiosa, e a do profissional é a de cunho ético-profissional de preservação da vida. Porém, a sensibilidade do profissional ao manifestar sua compreensão sobre o contexto em que este indivíduo se insere proporciona confiança e gera tranquilidade para o curso do tratamento.

Quando há compreensão de que todo ser humano se insere em um contexto que influi em suas ações e reações na vida cotidiana, este é um primeiro passo para que se desenvolva uma relação interpessoal de respeito mútuo, profícua para que haja a prática da humanização (Martins, 2001).

Apesar de o usuário estar em um cenário hospitalar e precisar de procedimentos, muitos deles de caráter invasivos ao seu organismo, não perde a sua condição cidadã e nem a sua subjetividade, devendo ser ouvido e participar das negociações necessárias ao tratamento.

Como eu já vi várias vezes. Todo mundo é igual. $\varepsilon$ não éassim, cada paciente, cada caso, mesmo sendo a mesma coisa [doença], mas cada um tem uma reação diferente, ao medicamento... a tudo (UF43-05).

A unidade de registro eleita para exemplificar esta discussão (UF43-O5) mostra a importância do conhecimento científico aliado à visão holística e contextual do ser humano (Corbani e col., 2009). Científico, pois há necessidade de conhecimento da reação físico-química de um medicamento, por exemplo. E holística (contextual), pois permite distinguir as diversas reações que o usuário possa apresentar, diferenciando uma reação fisiopatológica de uma reação psicológica, relacionada ao ambiente em que está inserido.

Isto posto, retomemos a teoria de Florence Nightingale que introduziu o ambiente na análise de ações de prevenção de enfermidades, tratamento e recuperação de doentes, orientando a prática de enfermagem (Carraro, 2004). Esta retomada aplica-se na discussão do momento, mormente no que se refere à humanização do cuidado, pois muitos dos aspectos aqui tratados guardam nexos importantes com o ambiente no qual se insere os sujeitos do cuidado.

Ao se falar do contexto que engloba o indivíduo, não se pode deixar de considerar o contexto situacional do hospital no momento da produção dos dados desta pesquisa. Este permitiu que se observasse a preocupação dos profissionais de saúde em evitar o contágio e a disseminação da bactéria Acinetobacter, visto que o hospital passava por um momento de surto deste microorganismo. As espécies de Acinetobacter geralmente são consideradas não patogênicas em indivíduos saudáveis. Entretanto, diversas espécies persistem em ambientes hospitalares e causam infecções graves que ameaçam a vida de pacientes comprometidos (Gerischer, 2008).

Estas situações de infecção hospitalar, em geral, comprometem em muito o estabelecimento de relações entre os profissionais e os usuários, haja vista que implica em diminuição do contato físico, além de comprometer a frequência das visitas ao leito, limitadas às situações dos protocolos clínicos, que visam o controle e a prevenção das infecções hospitalares (Richtmann, 2002).

Por conta de tal infecção, cada leito era verificado por um membro da Comissão de Controle de Infecção Hospitalar (CCIH), além da preocupação com a utilização de Equipamentos de Proteção Individual (EPI), como luvas, capotes e máscaras. Havia também preocupação em explicar ao usuário sobre a situação pela qual o hospital estava passando, apesar de haver alguns problemas de comunicação, a serem explorados no elemento constitutivo da categoria, explicitado a seguir (Caderno de campo, 09/02/2010).

\section{Comunicação/Diálogo, Sociabilidade}

Essas duas vertentes emergiram com muita incidência dos conteúdos analisados, em coocorrência com a relação profissional-usuário.

O diálogo produz, intermedeia e conduz as relações de cuidar, por isso a comunicação precisa ir 
além de um mecanismo comunicacional para um carreador de significações e sentimentos ao instaurar o encontro profissional-usuário no processo do cuidado em enfermagem (Schaurich e Crossetti, 2008).

Eu acho que o médico deve ter... entre o médico e o paciente tem que ter um diálogo para ele explicar o que o paciente tem, o paciente precisa saber. (UM44-01).

Escutar ao paciente o que ele está sentindo. Acreditar no que ele fala e assim como o acompanhante, também com a família (UF43-05)

O grande problema que eu acho, assim... do paciente, hoje, é o direito à informação. Ele não sabe o que ele tem... [...] Isso seria interessante... (UM50-04)

o médico diz: 'o senhor tem uma neoplasia'... eu não vou ter que ir lá no Google para saber o que é neoplasia para depois eu entender o que eu tenho, entendeu? (UM50-04).

O cuidar em saúde e, em especial o de enfermagem, pode ser entendido como o lócus de aplicação de conhecimentos científicos na prática profissional, associando a habilidade da comunicação e respeitando o paciente como um ser humano (Balduino e col., 2009).

As unidades de registros referenciadas remetem à importância que a comunicação profissional-usuário ganha no contexto do cuidado em saúde, mormente no hospitalar. Comunicação esta que cumpra sua finalidade de ser compreensível ao usuário e atenda às suas expectativas e esclareça suas dúvidas.

Interessante observar que em uma das unidades de registro exemplificadas, um dos sujeitos faz referência a uma ferramenta de busca virtual (internet) que lhe dá a possibilidade de ampliar suas informações. Apesar disso, ela não substitui o diálogo com o profissional, que ganha status no âmbito da comunicação. Isto mostra que apesar de vivermos atualmente em uma sociedade dita "da informação" (Santos, 2004), e termos um amplo acesso às diversas bases virtuais, estas não substituem, ainda, ao menos à luz dos dados aqui apresentados, a comunicação e troca de informação que se dão no encontro presencial entre profissionais e usuários (Ferreira, 2006).
Nesta discussão, consideram-se os direitos do paciente no que se refere ao acesso à informação sobre seu diagnóstico e tratamento, constituindo-se em um dos elementos da PNH, uma vez que esta remete ao respeito à cidadania dos usuários (Santos, 2007).

Ainda em destaque, identifica-se que a relação profissional-usuário transcende a comunicação verbal e é assim identificada como expressão de humanização pelos usuários.

Tem uma equipe que chora quando morre alguém aqui...é normal (UFo1-R1o).

Eu vi uma cliente aos prantos, inconformada e desamparada [...] uma enfermeira se aproximou, conversou, explicou o que havia acontecido, amparou-a com o toque de suas mãos e a levou a um lugar mais confortável (Caderno de Campo, o9/02/2010).

A demonstração de sensibilidade pelos profissionais não fica alheia à observação dos usuários, que registram tais manifestações como exemplos de expressão de humanização. A empatia e a facilidade em compartilhar momentos difíceis vividos pelos usuários e seus familiares contribuem para a construção e manutenção de laços afetivos interpessoais.

Outro exemplo de expressão humanizadora do cuidado, objetivada através da comunicação, pode ser extraído dos registros feitos no diário de campo quando um usuário com a acuidade auditiva diminuída estava sentado no leito e uma técnica de enfermagem se aproximou, dirigindo-se a ele pelo nome, explicando, com clareza, calma e de forma precisa, todo o procedimento que seria executado. Falou da sua finalidade, repetindo em um tom mais alto, porém mantendo a calma, visando não haver intercorrências durante o procedimento. Durante este, a profissional conversou com o usuário e, ao final, certificou-se sobre a situação do paciente, mantendo-o estável. (Caderno de campo, o9/02/2010).

Outro dado advindo da etapa de aplicação da observação participante que mostra elementos da prática do cuidado que concorrem para a formação das ideias dos usuários sobre a humanização alude à vivência de uma usuária que, após alguns procedimentos de enfermagem executados foi questionada sobre como se sentia em relação à profissional de enfermagem que cuidara dela. A esta abordagem, a usuária fez o seguinte relato: 
Ela é um amor, me faz sentir em casa, quando a gente conversa, esqueço que estou aqui (Caderno de campo, 22/02/2010).

Esta avaliação se alia a outras que mencionam a força que uma interação positiva tem para a qualificação do cuidado no ambiente hospitalar. Levando-se em conta que o tema central indutor da formação dos discursos foi a humanização, deduz-se que as características aqui retratadas remetem à sua importância na construção de uma representação social sobre este objeto.

Essa troca que nós estamos tendo. Um bom dia. Como é que você passou a noite? (UF59-01).

Porque às vezes elas brincam, umas são mais agradáveis. Aquelas que brincam mais, ele sorri, ele conversa, ele grava o nome (UF43-05)

Uma pessoa que entra sorrindo está nos dizendo algo... está dizendo que ela é uma pessoa acessível, que ela está aberta ao diálogo, às perguntas... é muito mais fácil você... quanto mais para uma pessoa tímida, você ter acesso àquele profissional não é? [...] Uma pessoa sorridente, alegre passa mais confiança... (UM50-04).

$\mathrm{Na}$ análise de conteúdo do corpus de dados oriundo das entrevistas, identificam-se muitas unidades de registro que aludem que a humanização do cuidado está fortemente centrada nas expressões humanas entendidas pelos usuários como "humanizadoras" da relação, com ênfase na emoção, afetividade que se expressam no carinho dispensado no cuidado a eles. Tais formas de pensar a humanização objetivam-se na citação da palavra "coração", que traduz esta gama de sentimentos ditos humanizadores.

Não deixando de ser enfermeiras, mas botando o seu coração, porque nós somos carentes, nós precisamos de carinho, porque isso ajuda na nossa cura... Respeito! (UF59-01).

Isto vem reforçar a tendência majoritária dos usuários em conformar as RS da humanização pautadas em elementos subjetivos que constroem relações interpessoais de cunho afetivo e solidário (Matsuda e col., 2003; Brito e Carvalho, 2010; Araújo e Ferreira, 2011).
As afirmações até aqui postas ganham respaldo na observação de que há, também, expressões que denotam a não humanização, que se colocam em polos contrários ao que até então se discutiu, mostrando a complexidade deste processo, na evidência do necessário investimento que se deva ter no campo das relações entre profissional-usuário e na prática clínica do atendimento.

[Alguns atendimentos] $\varepsilon$ É mecânico mesmo. Porque também eu acho que tem... tem muito paciente... Não dá realmente para ficar uma hora conversando com cada paciente, mas pelo menos ser mais sensivel, não é? Ainda mais paciente de idade, não é? Que não entende, não escuta, às vezes, não consegue compreender que a pessoa está passando no trabalho. (UF43-05).

Eu vi certas cenas que nossa... é... deprimente! Tipo, por exemplo, vi pessoas praticamente gritando por socorro, "pelo amor de Deus" e o... a pessoa, tanto médico quanto enfermeiro, passar como se aquilo fosse um lixo, entende? Aquilo ali me doeu muito, porque eu acho que quem trabalha com saúde cuida de vida, entende? [...] ninguém é capaz de ao menos lançar um olhar? Que possa ajudar aquelas pessoas. [...] Está uma vergonha! [...] É muita frieza de coração (UF55-02).

Os elementos até aqui discutidos mostram exemplos de expressões humanizadoras e não humanizadoras, presentes na assistência ao usuário hospitalizado, muitas ligadas ao micro espaço das relações entre profissionais e usuários; no entanto, há que se considerar também os inúmeros problemas do cotidiano hospitalar que, por vezes, configuram-se em obstáculos à aplicação dos preceitos da Política Nacional de Humanização (PNH) - HumanizaSus (Brasil, 2004).

\section{Política gestora da saúde-assistência: elementos que implicam a humanização}

Esta categoria abrange os elementos constitutivos que remetem à dimensão política caracterizada, mais objetivamente, na gestão da instituição, no seu nível mais macro e também micro.

\section{Gestão, Infraestrutura e organização}

Em relação à gestão, as unidades de registro que permitiram esta classificação temática aludem, em seu conteúdo, às questões ligadas às necessidades 
de infraestrutura e organização. Pela experiência da falta, percebe-se a importância de tais elementos na proposição do cuidado/assistência humanizada.

Tudo tem que haver um comando. [...] A diretoria comanda o hospital. Então eu acho que a diretoria devia se programar mais entendeu? (UM67-02)

O erro está na administração, nos políticos, na liberação das verbas, na gestão de um modo geral (UM50-04).

Os usuários entendem que mesmo os profissionais querendo implantar os preceitos propostos pela PNH na área hospitalar, o problema maior está no plano gestor e atividades gerenciais, tanto no nível macro das políticas como no micro espaço do hospital. O profissional que cuida está na ponta de uma assistência que se não for bem gerida e suprida de condições de oferta pode ficar comprometida na sua operacionalização (Backes e col., 2007).

Muitas questões foram levantadas em relação à infraestrutura e organização, porém alguns itens foram mais frequentes quando ao corpus de dados aplicou-se a técnica de análise de ocorrência: o horário para cuidar do usuário, administrar medicações e realizar procedimentos, organização e cuidado com o material, quantidade de profissionais e condições de trabalho e atendimento.

Deveria ter um horário para cuidar do paciente, remédio na hora certa (UF54-O3 e UM44-01).

Mas eu já tenho nojo das vasilhas, porque não tem assepsia normal. Acabou de usar a comadre, passa uma 'aguinha'e colocam pra lá. Eu sei o que a amiga tem? [...] Aí é que acontece o contágio! [...] Isso que é o perigo! (UF59-01).

Mais... mais condições de trabalho. Profissionais. Mais materiais de trabalho. Equipamentos. Acho que isso podia melhorar (UM50-04).

Ah! Tem bem poucos profissionais. À noite, então, vira um caos. São só dois ou três para quatro ou cinco enfermarias... é bem difícil! [...] é além da capacidade, do alcance deles [...]. Tem pouca gente para muito paciente (UM50-04).

Caso de como está, seria um atendimento melhor, mais rápido não é? As pessoas que... são atendidas saírem satisfeitas (pausa curta) e não saírem criticando (UM50-04).
A infraestrutura de um hospital atua como um dos pilares da gestão para que o usuário sinta-se acolhido e satisfeito com a assistência prestada (Ramos e Lima, 2003). Desta infraestrutura fazem parte as condições de oferta da assistência, que envolvem tanto a quantidade e qualidade dos recursos humanos quanto materiais e, em vista disso, observa-se que em algumas situações, é o usuário que precisa supri-las para garantir a continuidade do tratamento. Nesta consideração, destaca-se a situação financeira da maioria dos sujeitos deste estudo, que corresponde a 1-2 salários mínimos.

Tanto falta que eles pedem pra pessoa trazer, não é? Trago os remédios... muitos. (pausa longa para pegar o medicamento na bolsa) está vendo? [...] Eu moro longe. [...] Não tenho carro, entendeu? [...] Aí tem a minha filha que trabalha, pega um táxi evem trazer água pra mim, trazer roupa... (UM67-02).

As questões de gestão político-financeira da saúde comprometem a execução da assistência pública e a sua gratuidade, uma vez que o conteúdo explicitado na unidade de registro em tela mostra, claramente, que a família dos usuários precisa contribuir diretamente com o financiamento do tratamento sob pena de não tê-lo.

O fato de trazer à luz desta discussão a condição de renda dos sujeitos não implica considerar que a gratuidade deva ser direcionada somente à parte da população mais carente, haja vista o princípio do Sistema Único de Saúde (SUS) de universalidade na saúde (Brasil, 1990). No entanto, há que se considerar que esta camada da população vivencia em seu cotidiano dificuldades concretas de atendimento de suas necessidades básicas, mormente aquelas diretamente implicadas em gastos financeiros, como alimentação, transporte, moradia, entre outras.

\section{Conclusão}

Os elementos constitutivos das concepções dos usuários hospitalizados sobre a humanização correspondem tanto às questões de caráter objetivo (gestão, mudança nas práticas e comportamentos) como de caráter subjetivo (empatia, relações profissional-usuário e questões emotivas), o que indica que a humanização tem uma vertente mais ampla, que atravessa de forma mais geral os grupos 
sociais, e uma vertente mais restrita, que responde aos contextos situacionais das vivências cotidianas dos sujeitos.

A detecção de tais elementos é reiterativa de resultados de pesquisas já realizadas sobre a humanização, o que mostra o necessário investimento que deve ser feito em políticas de valorização e qualificação dos recursos humanos que atuam no hospital. 0 fator humano emerge como principal qualidade da humanização no cenário hospitalar. Investimentos no preparo do profissional para que ele tenha uma abordagem mais humana e menos protocolar que em nada facilita a aproximação do usuário e, portanto, dificulta a criação de vínculo e relação de confiança, é condição para que se avance na implantação da PNH.

Para a implantação dos preceitos da PNH na área assistencial, ainda há enormes obstáculos, principalmente no que tange à gestão e às políticas de dimensionamento e aplicação de recursos. Não obstante, são passíveis de serem ultrapassados. Ao profissional cabe analisar o seu cotidiano, suas ações, como elas são interpretadas por aqueles que a usufruem, pois é ao usuário que o cuidado é dirigido e sua avaliação é um importante indicador de qualidade.

Os resultados desta pesquisa mostram que a humanização no contexto hospitalar traz uma importante vertente de cunho político e abrangente, não se restringindo ao campo das relações interpessoais e individuais que se travam no cuidado, embora esta seja de grande evidência e marque sobremaneira as concepções dos usuários sobre este objeto.

O campo da informação, da comunicação de massa, as questões éticas implicadas na garantia dos direitos dos pacientes, as condições de oferta dos serviços, o dimensionamento e a qualificação dos trabalhadores em face do quantitativo da clientela e da complexidade da assistência interferem em muito na qualidade do cuidado e naquilo que se entende por humanização, não passando despercebido pelos sujeitos, usuários hospitalizados.

Desta feita, a humanização do cuidado tem estreita relação com o binômio "saúde e sociedade", entendendo sociedade como o contexto no qual se inserem os sujeitos que participam do processo da saúde, como expressão das políticas e objeto mesmo a ser buscado como condição digna de vida.

\section{Referências}

ARAÚJO, F. P.; FERREIRA, M. A. Representações sociais sobre humanização do cuidado: implicações éticas e morais. Revista Brasileira de Enfermagem, Brasília, DF, v. 64, n. 2, p. 287-293, 2011. ARRUDA, A. Teoria das representações sociais e teorias de gêneros. Cadernos de Pesquisas, São Paulo, n. 117, p. 127-147, nov. 2002.

BACKES, D. S. et al. O produto do serviço de enfermagem na perspectiva da gerência da qualidade. Revista Gaúcha de Enfermagem, Porto Alegre, v. 28, n. 2, p. 163-170, 2007.

BALDUINO, A. F. A.; MANTOVANI, M. F.; LACERDA, M. R. O processo de cuidar de enfermagem ao portador de doença crônica cardíaca. Escola Anna Nery Revista de Enfermagem, Rio de Janeiro, v. 13, n. 2, p. 342-351, 2009.

BARDIN, L. Análise de conteúdo. São Paulo: Edições 70, 2011.

BRASIL. Lei $\mathrm{n}^{0} 8080$, de 19 de setembro de 1990. Dispõe sobre as condições para promoção, proteção e recuperação da saúde, a organização e o financiamento dos serviços correspondentes e da outras providências. Diário Oficial [da] República Federativa do Brasil, Brasília, DF, 20 set. 1990. Seção 1, p. 18055.

BRASIL. Ministério da Saúde. SecretariaExecutiva. Núcleo Técnico da Política Nacional de Humanização. Humaniza SUS: Política Nacional de Humanização: a humanização como eixo norteador das práticas de atenção e gestão em todas as instâncias do SUS. Brasília, DF, 2004. (Série B - Textos Básicos de Saúde). Disponível em: <http://bvsms.saude.gov.br/bvs/publicacoes/ humanizasus_2004.pdf> Acesso em: 21 ago. 2013.

BRITO, N. T. G.; CARVALHO, R. A humanização segundo pacientes oncológicos com longo período de internação. Einstein, São Paulo, v. 8, n. 2, p. 221227, 2010.

CARRARO, T. E. Os postulados de Nightingale e Semmelweis: poder/vital e prevenção/ contágio como estratégias para a evitabilidade das infecções. Revista Latino-Americana de Enfermagem, Ribeirão Preto, v. 12, n. 4, p. 650-657, 2004 . 
CORBANI, N. M. S.; BRÊTAS, A. C. P.; MATHEUS, M. C. C. Humanização do cuidado de enfermagem: o que é isso? Revista Brasileira de Enfermagem, Brasília, DF, v. 62, n. 3, p. 349-354, 2009.

FERREIRA, M. A. A comunicação no cuidado: uma questão fundamental na enfermagem. Revista

Brasileira de Enfermagem, Brasília, DF, v. 59, n. 3, p. 327-330, 2006.

GEERTZ, C. A interpretação das culturas. Rio de Janeiro: Livros Técnicos e Científicos, 1989.

GERISCHER, U. Acinetobacter molecular biology. Norfolk: Caister Academic Press, 2008.

MARTINS, M. C. F. N. Humanização das relações assistenciais: a formação do profissional de saúde. São Paulo: Casa do Psicólogo, 2001.

MATSUDA, L. M.; SILVA, N.; TISOLIN, A. M. Humanização da assistência de enfermagem: estudo com clientes no período pós-internação de uma UTI-adulto. Acta Scientiarum:Health Sciences, Maringá, v. 25, n. 2, p. 163-170, 2003.

MORIN, E. Introdução ao pensamento complexo. Porto Alegre: Sulina, 2011.

MOSCOVICI, S. Representações sociais:

investigações em psicologia social. Rio de Janeiro: Vozes, 2010.

NASCIMENTO-SCHULZE, C. M.; CAMARGO, B. V. Psicologia social, representações sociais e métodos. Temas em Psicologia, Ribeirão Preto, v. 8, n. 3, p. 287-299, 2000.
OLIVEIRA, M. S. B. S. Representações sociais e sociedade: a contribuição de Serge Moscovici. Revista Brasileira de Ciências Sociais, São Paulo, v. 19, n. 55, p. 180-186, 2004.

RAMOS, D. D.; LIMA, M. A. D. S. Acesso e acolhimento aos usuários em uma unidade de saúde de Porto Alegre, Rio Grande do Sul, Brasil. Cadernos de Saúde Pública, Rio de Janeiro, v. 19, n. 1, p. 27-34, 2003.

RICHTMANN, R. Guia prático do controle de infecção hospitalar. São Paulo: Soriak, 2002.

SANTOS, N. L. Sociedade da informação: mudanças e desafios psicossociais no contexto sócio-laboral. In: GOUVEIA, L.; GAIO, S. (Org.). Sociedade da informação: balanço e implicações. Porto: Universidade Fernando Pessoa, 2004. p. 255-270.

SANTOS, F. S. B. Perspectivas da avaliação na Política Nacional de Humanização em Saúde: aspectos conceituais e metodológicos. Ciência e Saúde Coletiva, Rio de Janeiro, v. 12, n. 4, p. 9991010, 2007.

SCHAURICH, D.; CROSSETTI, M. G. O. O elemento dialógico no cuidado de enfermagem: um ensaio com base em Martin Buber. Escola Anna Nery Revista de Enfermagem, Rio de Janeiro, v. 12, n. 3 , p. 544-548, 2008.

TOSCANO, C. M. As campanhas nacionais para detecção das doenças crônicas nãotransmissíveis: diabetes e hipertensão arterial. Ciência e Saúde Coletiva, Rio de Janeiro, v. 9, n. 4, p. 885-895, 2004. 